\title{
The need for revised standards for skinfold thickness in infancy
}

\author{
A A Paul, T J Cole, E A Ahmed, R G Whitehead
}

\begin{abstract}
Skinfold standards provide a useful indication of subcutaneous fat. To evaluate skinfold thickness of 252 Cambridge infants over the first 2 years of age, SD scores relative to the Tanner standards were calculated, taking account of skewness in the standards. Cambridge SD scores were low, varying according to age from -1.2 to -1.8 for triceps and -0.6 to -1.2 for subscapular skinfolds. The Tanner skinfold standards were last revised 30 years ago, at a time of high prevalence of infantile obesity, and the present and other studies indicate that infants are now thinner. There is a need for new skinfold standards to reflect this change. Since the Cambridge infants contributed to the recent British height and weight references, it is suggested that their skinfold measurements could also serve as reference points.

(Arch Dis Child 1998;78:354-358)
\end{abstract}

Keywords: skinfolds; standards; SD scores

Skinfold thickness is often measured in infancy to give an index of the deposition of body fat. ${ }^{1-4}$ The procedure is relatively non-invasive and requires only simple technology, although it does require careful training of observers. Standards have been published for triceps and subscapular skinfold thickness, ${ }^{5}$ but they are readily available in chart form only. It is not easy therefore to express measurements as SD scores relative to the standard. SD scores offer important advantages over centile graphical presentations. Multiple anthropometry measures can be presented on the same scales, and a sensitive assessment of growth faltering is more readily identified as the downward deviation from a horizontal line. ${ }^{67}$

Calculating SD scores is relatively straightforward when the variable in question is normally distributed, such as height, but not so when there is skewness present, as in weight and also skinfolds. The LMS statistical procedure of $\mathrm{Cole}^{8}$ deals with this skewness and enables SD scores to be calculated from any dataset by deriving values for the Box-Cox power (L), indicating skewness, median (M), and coefficient of variation (S). Centiles can also be prepared from the dataset.

The Tanner skinfold standards are now nearly 30 years old, and there is abundant evidence that for infants the centiles presented are considerably higher than more recent measurements. ${ }^{4-12}$ Differences in feeding practices are held to be largely responsible.
As there were no recent data on large numbers of British infants, triceps and subscapular skinfold were measured in 252 normal infants, comprising the Cambridge infant growth study. In order to calculate SD scores, values for $L, M$, and $S$ were required for the Tanner skinfold standards. Davies et al have calculated these three parameters from 1 to 18 years, ${ }^{13}$ and the present paper extends this analysis to derive LMS values for the first year of life.

\section{Methods}

SUBJECTS

We studied 252 infants (135 boys, 117 girls) longitudinally from birth to 2 years. All weighed $2.33 \mathrm{~kg}$ or more at birth, and were over 35 weeks' gestation, these data being obtained from the maternity hospital records. Mothers were recruited antenatally through the Cambridge City District midwives in four cohorts from January 1984 to September 1988. On each occasion, approximately 100 sequential deliveries were requested within a three month time window, and after exclusion of those due to move away (14\%), not willing $(12 \%)$, domestically unsuitable $(6 \%)$, preterm $(1.5 \%)$, or infant deaths $(1.5 \%)$, the remaining $65 \%$ of those on the midwives' lists were measured until at least 24 weeks of age. Ninety eight per cent of the infants were white. Details of the infants studied are shown in table 1 . Just over half the fathers $(56 \%$ for the boys and $55 \%$ for the girls) belonged to the non-manual social classes (I, II, and IIINM), ${ }^{14}$ a proportion representative of Cambridge. ${ }^{15}$ The infants' weight, length, head circumference, mid-upper arm circumference, and triceps and subscapu-

Table 1 Characteristics of the infants in the Cambridge infant growth study

\begin{tabular}{lll}
\hline & $\begin{array}{l}\text { Boys } \\
(n=135)\end{array}$ & $\begin{array}{l}\text { Girls } \\
(n=117)\end{array}$ \\
\hline $\begin{array}{lll}\text { Birth weight (kg, mean (SD)) } \\
\text { Parity (\%) }\end{array}$ & $3.38(0.50)$ & $3.40(0.40)$ \\
1 & 38 & 48 \\
2 & 46 & 28 \\
3 or more & 16 & 24 \\
Breast feeding (\%) & & \\
Birth & 86 & 88 \\
12 weeks & 67 & 69 \\
24 weeks & 56 & 61 \\
52 weeks & 21 & 21 \\
Introduction to solids & & \\
Mean age (weeks (SD)) & $13.6(4.0)$ & $14.5(4.5)$ \\
8 weeks (\%) & 10 & 4 \\
12 weeks (\%) & 55 & 35 \\
16 weeks (\%) & 76 & 78 \\
24 weeks (\%) & 100 & 97 \\
Weight (kg, mean (SD)) & & \\
12 weeks & $6.00(0.70)$ & $5.57(0.62)$ \\
24 weeks & $7.70(0.84)$ & $7.20(0.78)$ \\
52 weeks & $9.88(1.02)$ & $9.29(0.95)$ \\
104 weeks & $12.30(1.37)$ & $11.81(1.07)$ \\
\hline
\end{tabular}


Table 2 Numbers of infants measured for skinfolds at each age in the Cambridge infant growth study

\begin{tabular}{ccc}
\hline Age (weeks) & Boys & Girls \\
\hline 4 & 134 & 116 \\
8 & 135 & 116 \\
12 & 135 & 116 \\
16 & 133 & 117 \\
20 & 135 & 116 \\
24 & 134 & 115 \\
28 & 130 & 116 \\
32 & 133 & 116 \\
36 & 134 & 115 \\
40 & 131 & 114 \\
44 & 130 & 114 \\
48 & 129 & 114 \\
52 & 130 & 115 \\
65 & 91 & 91 \\
78 & 121 & 114 \\
104 & 118 & 110 \\
\hline
\end{tabular}

lar skinfolds were measured at home every four weeks for the first year, then at 15 (except for the first cohort), 18, and 24 months. On a few measurement occasions it was not possible to obtain skinfolds from one or two infants. Ninety one per cent of those starting continued to 2 years, as shown in table 2 , and further follow up was made, but is not reported here. Ethical approval was granted by the ethics committees of the Dunn Nutrition Centre and the Cambridge Area Regional Health Authority.

SKINFOLD MEASUREMENTS

Triceps and subscapular skinfold thickness measurements were made on the left side using Holtain calipers, essentially following the techniques of Tanner et al, ${ }^{5}$ but making modifications more appropriate for infants to accommodate their constant activity. Subscapular skinfold was easier to measure and was more reliable than tricipital.

For the triceps measurement, the arm was firmly held extended by the mother and the skinfold measured half way between the acromial process and the olecranon, the calipers being applied immediately above the pinch. This position was found to be easier to use on the infant's small arm than the normally recommended position below the pinch shown in standard illustrations. Two readings were recorded, and a third if these two differed greatly. The mean was used.

At young ages, subscapular skinfold was taken with the infants lying prone on the mothers' lap, but once they could sit-after about 6 months - the measurement was made in the sitting position. The skinfold was taken at an oblique angle below the left scapula, the caliper being applied immediately above this point. Duplicate measurements were recorded, and the mean used.

The majority $(77 \%)$ of the measurements were carried out by one observer (A), with two others $(\mathrm{B}, 12 \%$;, $6 \%)$ joining the study after the initial year. Two further observers provided holiday cover. Ninety four per cent of the tricipital duplicates and $97 \%$ of the subscapular duplicates were within $\pm 5 \%$ of the measurements, thus comparing favourably with the requirement that at least two thirds of measurements should fall within this bracket. ${ }^{5}$

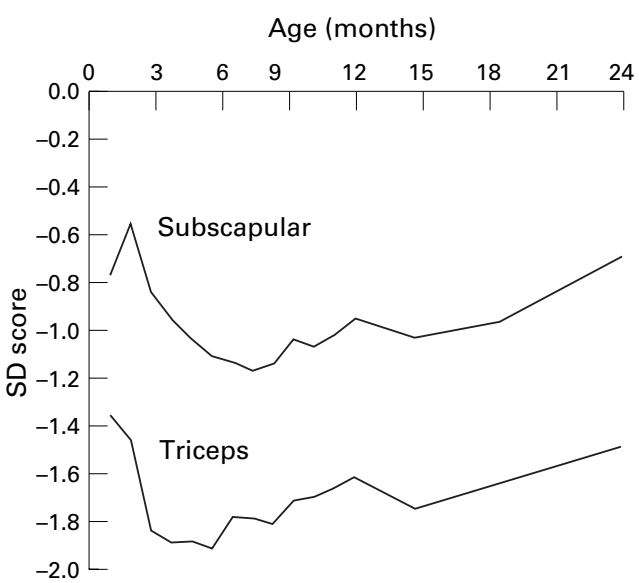

Figure 1 Mean SD scores of triceps and subscapular skinfold thickness of Cambridge infant growth study infants relative to the Tanner standards. ${ }^{5}$ For numbers at each age, see table 2.

\section{CALCULATION OF SD SCORES}

SD scores for triceps and subscapular skinfolds of Cambridge infants relative to the Tanner standards were calculated using the formula:

$$
\text { SD score }=\frac{\left[\frac{\text { Skinfold measurement }}{\mathrm{M}}\right]^{\mathrm{L}}-1}{\mathrm{~L} . \mathrm{S}}
$$

where $\mathrm{L}=$ Box-Cox power, $\mathrm{M}=$ median, and $S=$ coefficient of variation of the Tanner standards as derived below during the first year, and using the values presented by Davies et al from 1 to 2 years. ${ }^{13}$

CALCULATION OF LMS VALUES FROM THE TANNER STANDARDS

The procedure, as described in detail by Davies et $a l,{ }^{13}$ requires a starting point of centile values. Since the Tanner skinfold centiles are available in chart form only, ${ }^{5}$ it was necessary to read the untransformed values off the charts. A Hewlett Packard graph plotter was used on enlarged copies of the charts, the precise point being identified at the crossing of each centile line with each 0.1 year age point from 0 to 0.9 years. The coordinates were automatically logged by the plotter.

$\mathrm{L}, \mathrm{M}$, and $\mathrm{S}$ were calculated following the procedure of Davies et al. ${ }^{13}$ For all centiles, agreement was very close $( \pm 0.2 \mathrm{~mm})$ between the calculated values and the original ones from which they had been derived, which is in accordance with data obtained from standard skinfold centiles at later ages. ${ }^{13}$

\section{Results}

Calculated L, M, and S values for the Tanner triceps and subscapular skinfold standards in the first 2 years are presented in table 3 . Over the first 6 months, the L parameter for triceps rose steeply to a peak of +1.5 , indicating an increasingly negative skewness, and then fell again. The skewness of the subscapular skinfold showed a different pattern, starting between 0 and +1 and gradually falling close to 0 , indicating positive skewness.

SD scores for triceps and subscapular skinfolds of the Cambridge infants in relation to the Tanner standards are shown in fig 1. Triceps 
Table $3 L M S^{\star}$ parameters for triceps and subscapular skinfolds for the Tanner Standards for boys and girls aged 0 to 2 years

\begin{tabular}{|c|c|c|c|c|c|c|c|c|c|c|c|c|}
\hline \multirow{3}{*}{$\begin{array}{l}\text { Age } \\
\text { (years) }\end{array}$} & \multicolumn{6}{|c|}{ Triceps } & \multicolumn{6}{|c|}{ Subscapular } \\
\hline & \multicolumn{3}{|l|}{ Boys } & \multicolumn{3}{|l|}{ Girls } & \multicolumn{3}{|l|}{ Boys } & \multicolumn{3}{|l|}{ Girls } \\
\hline & $L$ & $M$ & $S$ & $L$ & $M$ & $S$ & $L$ & $M$ & $S$ & $L$ & $M$ & $S$ \\
\hline 0.05 & 0.60 & 7.41 & 0.22 & 0.66 & 7.52 & 0.17 & 0.16 & 7.04 & 0.24 & 0.64 & 7.12 & 0.21 \\
\hline 0.10 & 0.65 & 8.00 & 0.22 & 0.65 & 7.99 & 0.18 & 0.19 & 7.26 & 0.24 & 0.64 & 7.51 & 0.21 \\
\hline 0.20 & 0.53 & 9.49 & 0.23 & 0.63 & 9.13 & 0.19 & 0.16 & 7.95 & 0.25 & 0.40 & 8.35 & 0.23 \\
\hline 0.30 & 0.72 & 10.92 & 0.22 & 0.51 & 10.18 & 0.20 & 0.23 & 8.55 & 0.26 & 0.36 & 8.92 & 0.23 \\
\hline 0.40 & 1.06 & 11.68 & 0.22 & 0.39 & 10.75 & 0.21 & 0.23 & 8.77 & 0.27 & 0.27 & 9.00 & 0.24 \\
\hline 0.50 & 1.31 & 12.06 & 0.21 & 0.55 & 11.12 & 0.21 & 0.19 & 8.82 & 0.27 & 0.32 & 9.01 & 0.24 \\
\hline 0.60 & 1.41 & 12.23 & 0.21 & 0.71 & 11.37 & 0.22 & 0.16 & 8.82 & 0.27 & 0.34 & 8.93 & 0.24 \\
\hline 0.70 & 1.38 & 12.24 & 0.21 & 0.81 & 11.53 & 0.23 & 0.16 & 8.78 & 0.28 & 0.35 & 8.78 & 0.24 \\
\hline 0.80 & 1.33 & 12.17 & 0.22 & 0.91 & 11.66 & 0.23 & 0.10 & 8.66 & 0.28 & 0.30 & 8.60 & 0.24 \\
\hline 0.90 & 1.24 & 12.06 & 0.22 & 0.95 & 11.73 & 0.24 & 0.03 & 8.49 & 0.28 & 0.23 & 8.41 & 0.24 \\
\hline $1.00 \dagger$ & 1.20 & 12.01 & 0.22 & 0.83 & 11.76 & 0.24 & -0.06 & 8.26 & 0.29 & 0.33 & 8.32 & 0.24 \\
\hline $1.50 \dagger$ & 0.96 & 11.45 & 0.23 & 0.72 & 11.77 & 0.25 & -0.40 & 7.19 & 0.28 & 0.13 & 7.64 & 0.24 \\
\hline $2.00 \dagger$ & 0.68 & 10.86 & 0.24 & 0.65 & 11.55 & 0.25 & -0.48 & 6.58 & 0.27 & 0.01 & 7.20 & 0.25 \\
\hline
\end{tabular}

${ }^{\star} \mathrm{L}=$ Box-Cox power, $\mathrm{M}=$ median $(\mathrm{mm}), \mathrm{S}=$ coefficient of variation.

†From Davies et al. ${ }^{13}$

skinfold SD scores were markedly low, and declined to their lowest point at around -1.9 , corresponding to the 3rd centile on the Tanner standard, during the first 12 weeks. SD scores for subscapular skinfold were also below the Tanner standards, reaching their lowest value, -1.2 , that is, around the 10 th centile, at 28 weeks.

\section{Discussion}

Skinfold standards are generally used less critically than those relating to height and weight in growth assessment, and hence less attention has been paid to them. Although skinfolds are only weakly related to total body fat in infancy, ${ }^{11} 16$ their pattern of change over this period is consistent with estimates of body fat. ${ }^{2}$ Standards are of value in clinical settings, and in assessment of infant feeding, and it is important therefore that they reflect up to date expectations of subcutaneous fatness.

It has long been observed ${ }^{912}$ that the Tanner standards, revised in 1975, were considerably higher than subsequent reported measurements. This is confirmed in the present study. Tanner skinfold standards for the first year were based on 200 infants living in Derbyshire in $1968,{ }^{17}$ and, as was more common at that time, a not inconsiderable proportion of them $(35 \%)$ were overweight ( $>120 \%$ weight for age). ${ }^{18}$ In marked contrast, only three of the Cambridge infants ( $1 \%$ of those studied) developed obesity by the same definition. In drawing up the revised standards, Tanner ${ }^{5}$ was careful to emphasise that they were not a statement of what ought to be achieved, but rather a reflection of the situation current at that time. The early 1970s were indeed the peak of concern about infantile obesity. ${ }^{18-20}$ Breast feeding was in decline, only $19 \%$ of those in the Derbyshire group being fed this way for 16 weeks or longer, and solids were introduced remarkably early, at a mean age of 7 weeks. ${ }^{17}$ Since that time changes in the composition of formula milks, guidance on feed preparation to protect infants against excessive formula consumption, as well as a partial return to breast feeding have all contributed to leaner present day infants. The skinfold standards should now be revised again to reflect this change. The 1975 revised Tanner standards were notably higher during infancy than the standards they replaced, which had been based on Belgian infants in the absence of British data. ${ }^{21}$ In later childhood, there was less discrepancy between the two sets of Tanner standards, or indeed from other standard triceps skinfold measurements at that time. ${ }^{22}$ However, in contrast to the situation for infants, children have shown an increasing trend in triceps skinfold thickness

Table 4 Smoothed centiles and $L M S^{\star}$ parameters for triceps skinfold of boys and girls in the Cambridge infant growth study from 1 to 24 months

\begin{tabular}{|c|c|c|c|c|c|c|c|c|c|c|c|c|c|c|c|c|c|c|}
\hline \multirow{3}{*}{$\begin{array}{l}\text { Age } \\
\text { (months) }\end{array}$} & \multicolumn{9}{|l|}{ Boys } & \multicolumn{9}{|l|}{ Girls } \\
\hline & \multicolumn{7}{|c|}{ Centile (mm) } & \multirow[b]{2}{*}{$L$} & \multirow[b]{2}{*}{$S$} & \multicolumn{7}{|c|}{ Centile (mm) } & \multirow[b]{2}{*}{$L$} & \multirow[b]{2}{*}{$S$} \\
\hline & $2 n d$ & 9 th & $25 t h$ & $50 t h$ & $75 t h$ & $91 s t$ & 98th & & & $2 n d$ & 9 th & $25 t h$ & $50 t h$ & 75 th & $91 s t$ & 98th & & \\
\hline 1 & 3.86 & 4.47 & 5.16 & 5.94 & 6.81 & 7.79 & 8.87 & 0.18 & 0.208 & 3.42 & 4.13 & 4.88 & 5.67 & 6.51 & 7.38 & 8.29 & 0.64 & 0.215 \\
\hline 2 & 4.17 & 4.80 & 5.51 & 6.32 & 7.24 & 8.28 & 9.45 & 0.08 & 0.205 & 3.82 & 4.52 & 5.29 & 6.12 & 7.00 & 7.95 & 8.97 & 0.49 & 0.210 \\
\hline 3 & 4.32 & 4.95 & 5.68 & 6.50 & 7.44 & 8.51 & 9.73 & 0.03 & 0.203 & 4.04 & 4.75 & 5.52 & 6.36 & 7.28 & 8.28 & 9.35 & 0.39 & 0.208 \\
\hline 4 & 4.42 & 5.06 & 5.78 & 6.62 & 7.58 & 8.67 & 9.92 & 0.00 & 0.202 & 4.20 & 4.90 & 5.67 & 6.53 & 7.47 & 8.50 & 9.63 & 0.31 & 0.206 \\
\hline 5 & 4.49 & 5.13 & 5.87 & 6.71 & 7.68 & 8.78 & 10.06 & -0.02 & 0.202 & 4.32 & 5.01 & 5.79 & 6.65 & 7.61 & 8.67 & 9.83 & 0.25 & 0.205 \\
\hline 6 & 4.55 & 5.19 & 5.93 & 6.78 & 7.76 & 8.88 & 10.17 & -0.03 & 0.201 & 4.41 & 5.10 & 5.88 & 6.75 & 7.72 & 8.80 & 10.00 & 0.20 & 0.204 \\
\hline 7 & 4.59 & 5.24 & 5.99 & 6.85 & 7.83 & 8.97 & 10.27 & -0.04 & 0.201 & 4.48 & 5.17 & 5.95 & 6.83 & 7.81 & 8.91 & 10.13 & 0.16 & 0.204 \\
\hline 8 & 4.63 & 5.28 & 6.03 & 6.90 & 7.89 & 9.03 & 10.35 & -0.04 & 0.201 & 4.54 & 5.23 & 6.01 & 6.89 & 7.88 & 8.99 & 10.24 & 0.12 & 0.203 \\
\hline 9 & 4.66 & 5.32 & 6.07 & 6.94 & 7.94 & 9.09 & 10.42 & -0.04 & 0.201 & 4.60 & 5.28 & 6.06 & 6.94 & 7.94 & 9.06 & 10.32 & 0.10 & 0.202 \\
\hline 10 & 4.68 & 5.34 & 6.10 & 6.98 & 7.99 & 9.14 & 10.48 & -0.04 & 0.201 & 4.64 & 5.32 & 6.10 & 6.98 & 7.98 & 9.11 & 10.39 & 0.07 & 0.202 \\
\hline 11 & 4.70 & 5.37 & 6.13 & 7.01 & 8.02 & 9.18 & 10.52 & -0.04 & 0.202 & 4.67 & 5.36 & 6.14 & 7.02 & 8.02 & 9.16 & 10.44 & 0.06 & 0.201 \\
\hline 12 & 4.71 & 5.38 & 6.15 & 7.04 & 8.05 & 9.22 & 10.56 & -0.03 & 0.202 & 4.70 & 5.39 & 6.16 & 7.05 & 8.05 & 9.19 & 10.49 & 0.04 & 0.200 \\
\hline 15 & 4.74 & 5.42 & 6.19 & 7.09 & 8.11 & 9.29 & 10.64 & -0.02 & 0.202 & 4.78 & 5.46 & 6.23 & 7.12 & 8.12 & 9.27 & 10.57 & 0.02 & 0.199 \\
\hline 18 & 4.75 & 5.43 & 6.22 & 7.12 & 8.16 & 9.34 & 10.70 & 0.00 & 0.203 & 4.84 & 5.51 & 6.29 & 7.17 & 8.18 & 9.33 & 10.64 & 0.00 & 0.197 \\
\hline 21 & 4.75 & 5.44 & 6.23 & 7.14 & 8.18 & 9.37 & 10.73 & 0.01 & 0.204 & 4.89 & 5.57 & 6.34 & 7.22 & 8.23 & 9.37 & 10.68 & -0.01 & 0.195 \\
\hline 24 & 4.75 & 5.45 & 6.25 & 7.16 & 8.21 & 9.40 & 10.77 & 0.02 & 0.205 & 4.94 & 5.62 & 6.39 & 7.27 & 8.27 & 9.42 & 10.73 & -0.02 & 0.194 \\
\hline
\end{tabular}

${ }^{\star} \mathrm{L}=$ Box-Cox power; the 50th centile is the median, $\mathrm{M}$; $\mathrm{S}=$ coefficient of variation. 
Table 5 Smoothed centiles and LMS* parameters for subscapular skinfold of boys and girls in the Cambridge infant growth study from 1 to 24 months

\begin{tabular}{|c|c|c|c|c|c|c|c|c|c|c|c|c|c|c|c|c|c|c|}
\hline \multirow{3}{*}{$\begin{array}{l}\text { Age } \\
\text { (months) }\end{array}$} & \multicolumn{9}{|l|}{ Boys } & \multicolumn{9}{|l|}{ Girls } \\
\hline & \multicolumn{7}{|c|}{ Centile (mm) } & \multirow[b]{2}{*}{$L$} & \multirow[b]{2}{*}{$S$} & \multicolumn{7}{|c|}{ Centile ( $\mathrm{mm}$ ) } & \multirow[b]{2}{*}{$L$} & \multirow[b]{2}{*}{$S$} \\
\hline & $2 n d$ & 9 th & $25 t h$ & $50 t h$ & $75 t h$ & $91 s t$ & $98 t h$ & & & $2 n d$ & 9 th & $25 t h$ & $50 t h$ & $75 t h$ & $91 s t$ & 98 th & & \\
\hline 1 & 4.05 & 4.70 & 5.43 & 6.26 & 7.19 & 8.23 & 9.39 & 0.17 & 0.210 & 3.82 & 4.53 & 5.28 & 6.08 & 6.93 & 7.82 & 8.76 & 0.58 & 0.203 \\
\hline 2 & 4.51 & 5.17 & 5.92 & 6.80 & 7.81 & 8.97 & 10.32 & -0.03 & 0.207 & 4.30 & 4.97 & 5.73 & 6.59 & 7.55 & 8.62 & 9.82 & 0.16 & 0.206 \\
\hline 3 & 4.61 & 5.26 & 6.01 & 6.89 & 7.92 & 9.13 & 10.55 & -0.13 & 0.207 & 4.42 & 5.06 & 5.80 & 6.66 & 7.65 & 8.81 & 10.16 & -0.07 & 0.208 \\
\hline 4 & 4.59 & 5.22 & 5.97 & 6.84 & 7.88 & 9.10 & 10.55 & -0.19 & 0.208 & 4.44 & 5.05 & 5.76 & 6.61 & 7.62 & 8.82 & 10.27 & -0.23 & 0.209 \\
\hline 5 & 4.54 & 5.16 & 5.90 & 6.76 & 7.79 & 9.02 & 10.50 & -0.23 & 0.209 & 4.42 & 5.01 & 5.71 & 6.54 & 7.55 & 8.79 & 10.30 & -0.35 & 0.210 \\
\hline 6 & 4.48 & 5.10 & 5.83 & 6.69 & 7.72 & 8.95 & 10.44 & -0.26 & 0.211 & 4.39 & 4.96 & 5.64 & 6.47 & 7.48 & 8.73 & 10.31 & -0.43 & 0.211 \\
\hline 7 & 4.44 & 5.04 & 5.76 & 6.62 & 7.65 & 8.88 & 10.39 & -0.28 & 0.212 & 4.36 & 4.92 & 5.59 & 6.40 & 7.41 & 8.68 & 10.31 & -0.50 & 0.212 \\
\hline 8 & 4.39 & 4.99 & 5.71 & 6.56 & 7.58 & 8.82 & 10.34 & -0.29 & 0.213 & 4.33 & 4.87 & 5.53 & 6.34 & 7.35 & 8.63 & 10.30 & -0.55 & 0.213 \\
\hline 9 & 4.35 & 4.94 & 5.65 & 6.50 & 7.52 & 8.76 & 10.29 & -0.31 & 0.214 & 4.30 & 4.83 & 5.48 & 6.28 & 7.29 & 8.58 & 10.28 & -0.60 & 0.213 \\
\hline 10 & 4.30 & 4.89 & 5.59 & 6.44 & 7.45 & 8.69 & 10.22 & -0.32 & 0.215 & 4.26 & 4.79 & 5.43 & 6.23 & 7.23 & 8.52 & 10.24 & -0.63 & 0.214 \\
\hline 11 & 4.25 & 4.84 & 5.53 & 6.37 & 7.38 & 8.62 & 10.14 & -0.33 & 0.216 & 4.22 & 4.74 & 5.38 & 6.17 & 7.17 & 8.46 & 10.20 & -0.65 & 0.214 \\
\hline 12 & 4.20 & 4.78 & 5.47 & 6.30 & 7.31 & 8.54 & 10.06 & -0.34 & 0.217 & 4.19 & 4.70 & 5.33 & 6.11 & 7.10 & 8.40 & 10.15 & -0.67 & 0.215 \\
\hline 15 & 4.07 & 4.63 & 5.30 & 6.10 & 7.09 & 8.30 & 9.81 & -0.36 & 0.218 & 4.08 & 4.58 & 5.19 & 5.95 & 6.93 & 8.22 & 9.98 & -0.71 & 0.216 \\
\hline 18 & 3.96 & 4.50 & 5.15 & 5.94 & 6.91 & 8.10 & 9.60 & -0.37 & 0.220 & 4.00 & 4.49 & 5.09 & 5.84 & 6.81 & 8.09 & 9.87 & -0.74 & 0.218 \\
\hline 21 & 3.88 & 4.41 & 5.05 & 5.83 & 6.78 & 7.96 & 9.46 & -0.39 & 0.221 & 3.96 & 4.44 & 5.03 & 5.78 & 6.75 & 8.04 & 9.83 & -0.76 & 0.219 \\
\hline 24 & 3.81 & 4.33 & 4.96 & 5.73 & 6.67 & 7.85 & 9.34 & -0.40 & 0.222 & 3.93 & 4.41 & 5.00 & 5.74 & 6.70 & 8.00 & 9.81 & -0.77 & 0.220 \\
\hline
\end{tabular}

$\star \mathrm{L}=$ Box-Cox power; the 50th centile is the median, $\mathrm{M}$; $\mathrm{S}=$ coefficient of variation.

over the last 20 years and the 1990 measurements from the national study of health and growth $^{23}$ should now be the ones against which other evaluations are made.

Our results for Cambridge infants show a large deviation below the Tanner standards, particularly for triceps skinfold. Although our study contained a higher proportion of breast fed infants than is found nationally, ${ }^{24}$ it is unlikely that this is the reason for the particularly low triceps skinfold, as this did not differ according to type of milk feeding. ${ }^{25}$ Breast fed infants did, however, have a smaller subscapular skinfold compared to those receiving formula milk, but only by about $0.6 \mathrm{~mm} .^{25}$ The results of other studies covering the first year have been conflicting, with values for triceps and subscapular skinfold thickness that are greater, ${ }^{26}$ similar or less, ${ }^{27}$ or significantly less $^{2}$ in breast fed than in formula fed infants. Differences in timing of the introduction of solid foods and amounts given, as well as duration of breast feeding, are likely to contribute to these varying results.

There are few other recent measurements of skinfold thickness in British infants with which to compare the Cambridge data. Our results are slightly lower $(0.5$ to $1 \mathrm{~mm})$ than those found for other Cambridge infants ${ }^{11}{ }^{28}$ and a little further ( 1.0 to $1.5 \mathrm{~mm}$ ) below the triceps and subscapular skinfolds reported for other white infants. ${ }^{4}$ At 2 years of age though, the present data for subscapular skinfold are virtually identical to those reported for a large nationally representative sample, ${ }^{29}$ but again the triceps values are 1.5 to $2 \mathrm{~mm}$ lower. These differences between studies could be the result of measurement technique as much as feeding practice, and it is difficult to assess their importance in practice. More measurements are needed on different sets of nationally representative British infants so that the true situation is reflected.

To aid interpretation of skinfold measurements, standards provide an external point of comparison. At present, using the Tanner standards is likely to indicate that a study population is abnormally thin. In the absence of other published recent measurements, the
Cambridge infant growth study could be used as a reference point. It has the advantage that the same infants have contributed to the recent British height and weight standards, ${ }^{30}$ and also that the majority of the infants were fed in accordance with current Department of Health recommendations. ${ }^{10}$ Centiles for the Cambridge infants are shown in table 4 for triceps and table 5 for subscapular skinfolds. To enable SD scores to be calculated, LMS parameters are also given for the Cambridge infant growth study in tables 4 and 5 . These were derived using Cole's method. ${ }^{8}$ It should be borne in mind, however, that the Cambridge skinfolds appear to be at the lower end of the reported range, particularly the triceps, and that other study populations could yield higher values.

The derivation of the three parameters indicating skewness (L), median (M), and coefficient of variation (S) describes a dataset sufficiently for it to be used as a reference for evaluation. Centiles can be produced and SD scores relative to the reference dataset calculated. With the parameters presented here, it would be possible to achieve these objectives using either the Tanner standards or the Cambridge infant growth study. As the Tanner centiles are considerably higher than present day measurements of infant skinfold thickness, the Cambridge values may be preferable.

We are indebted to the parents and their infants for their participation in the study. We thank Penny Norris, June Grainger, and Sally Thornton for skinfold measurements, Ken trict midwives and staff at the Cambridge Maternity Hospital for their valued assistance.

1 Leung S, Davies DP. Infant feeding and growth of Chinese infants: birth to 2 years. Paediatr Perinat Epidemiol 1994;8:301-13.

2 Dewey KG, Heinig MJ, Nommsen LA, Peerson JM, Lonnerdal B. Breast-fed infants are leaner than formulafed infants at 1 y of age: the DARLING study. Am $\mathcal{F}$ Clin Nutr 1993;57:140-5.

3 Sann L, Durand M, Picard J, Lasne Y, Bethenod M. Arm fat and muscle areas in infancy. Arch Dis Child 1988;63:25660.

4 Warrington S, Storey DM. Comparative studies on Asian and Caucasian children. 1. Growth. Eur F Clin Nutr 1988; 42:61-7.

5 Tanner JM, Whitehouse RH. Revised standards for triceps and subscapular skinfolds in British children. Arch Dis Child 1975;50:142-5.

6 Cole TJ, Paul AA, Eccles M, Whitehead RG. The use of a multiple growth standard to highlight the effects of diet and infection on growth. In: Tanner JM, ed. Perspectives in the 
science of growth and development. Auxology 88. London: Smith-Gordon, 1989:91-100

7 Cole TJ. The use and construction of anthropometric growth reference standards. Nutr Res Rev 1993;6:19-50.

8 Cole TJ, Green PJ. Smoothing reference centile curves: the LMS method and penalized likelihood. Stat Med 1992;11: 1305-19.

9 Whitehead RG, Paul AA. Growth charts and the assessment of infant feeding practices in the western world and in developing countries. Early Hum Dev 1984;9:187-207.

10 Whitehead RG, Paul AA, Cole TJ. Diet and the growth of healthy infants. Fournal of Human Nutrition and Dietetics 1989;2:73-84.

11 Davies PSW, Lucas A. The prediction of total body fatness in early infancy. Early Hum Dev 1990;21:193-8.

12 Whitelaw A. Infant feeding and subcutaneous fat at birth and at one year. Lancet 1977;ii:1098-9.

13 Davies PSW, Day JME, Cole TJ. Converting TannerWhitehouse reference tricep and subscapular skinfold measurements to standard deviation scores. Eur f Clin Nutr measurements to

14 Office of Population Censuses and Surveys. Classification of occupations and coding index 1980. London: HMSO, 1980.

15 Office of Population Censuses and Surveys. 1991 Census. County report. Cambridgeshire, Part 2. London: HMSO, 1993.

16 de Bruin NC, van Velthoven KAM, de Ridder M, et al. Standards for total body fat and fat-free mass in infants. Arch Dis Child 1996;74:386-99.

17 Hutchinson-Smith B. Skinfold thickness in infancy in relation to birthweight. Dev Med Child Neurol 1973;15 628-34.

18 Hutchinson-Smith B. The relationship between the weight of an infant and lower respiratory infection. Med Officer 1970;123:257-62.

19 Taitz LS. Infantile overnutrition among artificially fed infants in the Sheffield region. BMF 1971;i:315-21.
20 Shukla A, Forsyth HA, Anderson CM, Marwah SM. Infantile overnutrition in the first year of life: a field study in Dudley, Worcestershire. BMF 1972;ii:507-15.

21 Tanner JM, Whitehouse RH. Standards for subcutaneous fat in British children. Percentiles for thickness of skinfolds over triceps and below scapular. BMF 1962;i:446-50.

22 Rona RJ, Altman DG. National Study of Health and Growth: standards of attained height, weight and triceps skinfold in English children 5 to 11 years old. Ann Hum Biol 1977;4:501-23.

23 Chinn S, Rona RJ. Trends in weight-for-height and triceps skinfold thickness for English and Scottish children, 19721982 and 1982-1990. Paediatr Perinat Epidemiol 1994;8: 90-106.

24 Martin J. Infant feeding 1990. London: HMSO, 1992.

25 Paul AA, Davies PSW, Whitehead RG. Infant growth and energy requirements: updating reference values. In: Walker $\mathrm{AF}$, Rolls BA, eds. Infant nutrition: issues in mutrition and toxicology 2. London: Chapman and Hall, 1994:117-41.

26 Salmenpera L, Perheentupa J, Siimes MA. Exclusively breast-fed healthy infants grow slower than reference infants. Pediatr Res 1985;19:307-12.

27 Saarinen UM, Siimes MA. Role of prolonged breastfeeding in infant growth. Acta Paediatr Scand 1979;68:245-50.

28 Paul AA, Black AE, Evans J, Cole TJ, Whitehead RG. Breastmilk intake and growth in infants from two to ten Breastmilk intake and growth in infants from two to ten 437-50.

29 Fox PT, Elston MD, Waterlow JC. Pre-school child survey. In: Sub-committee on nutritional surveillance: second report. DHSS report on health and social subjects, No 21. London: HMSO, 1981:64-84.

30 Freeman JV, Cole TJ, Chinn S, Jones P, White EM, Preece MA. Cross sectional stature and weight reference curves for the UK, 1990. Arch Dis Child 1995;73:17-24. 